NBER WORKING PAPER SERIES

\title{
REAL ASPECTS OF EXCHANGE RATE REGIME CHOICE WITH COLLAPSING FIXED RATES
}

Robert P. Flood

Robert J. Hodrick

Working Paper No. 1603

NATIONAL BUREAU OF ECONOMIC RESEARCH 1050 Massachusetts Avenue Cambridge, MA 02138

Apri 1985

Early versions of this paper were presented at the Econometric Society Meetings in December 1983 and at a National Bureau of Economic Research Mini-Conference held at the University of Chicago in May 1984. We thank the discussant, Joshua Aizenman, and other participants for their comments. We al so thank participants in workshops at Columbia University, University of Illinois, and Onio State University. This work was supported by a grant from the National Science Foundation. The research reported here is part of the NBER's research program in International Studies and project in Productivity and Industrial Change in the World Economy. Any opinions expressed are those of the authors and not those of the National Bureau of Economic Research. 
NBER Working Paper \#1603

Apri1 1985

Real Aspects of Exchange Rate Regime

Choice with Collapsing Fixed Rates

\section{ABS TRACT}

Typical evaluations of the choice of exchange rate regime employ a criterion function that depends on the real performance of the economy, and they focus on regimes that are expected to last indefinitely. This latter feature is strongly contradicted by the transitory nature of actual regines. This paper extends the recent literature on collapses of fixed exchange rate regimes with exogenous real sectors to examine how the predictions of two popular models for the determination of some real economic variables rust be modified when agents rationally perceive that the fixed rate regime will be transitory. The models studied are simple stochastic versions of the models in Dornbusch (1976) and Flood and Marion (1982).

Robert P. Flood Department of Economics Northwestern University Evanston, Illinois 60201 $312-491-3238$
Robert J. Hodrick

Finance Department

Kellogg Graduate School of Management Northwestera Uaiversity

Evanston, Illinois 60201 $312-491-8339$ 
Typical evaluations of the performance of an economy under alternative exchange rate regimes proceed under the assumption that exchange-rate regimes last forever. ${ }^{1}$ This assumption is a gross contradiction of the fact that exchange rate regimes are actually quite transitory. Countries never really followed the "rules of the game". under the Gold Standard, and it evolved into the Gold Exchange Standard. During the Great Depression currencles became inconvertible. The Bretton Woods system was planned as a system of fixed exchange rates, but it was recognized that countries would devalue and revalue their currencies when in "fundamental disequlibrium". Although this term was never formally defined, countries did devalue and revalue their currencies, often by large amounts, during the two decades preceding the breakdown of the system in 1971.

The purpose of this paper is to reexamine the determination of real output in two popular models of the open economy accounting explicitly for the transitory nature of fixed exchange rate regimes. Rational agents understand that an exchange-rate regime may be temporary, and they incorporate expectations of the collapse of the regime and its associated capital gains or losses into their behavioral functions. The models we examine are simple stochastic versions of the Dornbush (1976) model of exchange rate dynamics with flexible output and the Flood and Marion (1982) model of wage indexation in an open economy. We work with simplified versions of these models since our point is that some of the implications of the models are drastically aitered when we allow agents to act on their understanding of regime impermanence. These alterations are robust to more complex versions of the models, but since we are presenting some counterexamples, model complexity only obscures our points. Our work bullds on previous research on the temporary nature of government policies including Salant and Henderson (1978), Krugman (1979), Flood and Garber (1983, 1984) and Flood and Marion (1983). 
In Section 2 of the paper we develop our version of the Dornbusch model. For some configurations of the model, we demonstrate that the regime of permanently floating exchange rates always produces a higher unconditional variance of output than does a regime of permanently fixed exchange rates. This result is confirmed when we consider a temporary fixed-rate regime, although we find the disadvantage of a floating-rate regime diminishes as the possibility of an attack on a fixed rate regime rises. This result is an unsurprising extension of the original comparison between fixed and flexible exchange rates. What is surprising to us, however, is that output variance conditional on maintaining a fixed-rate regime which may collapse can be higher than output variance under floating rates. Intuitively, this measure of the conditional variance of real output corresponds to the sample or measured output variance during a fixed exchange rate regime that has not collapsed.

Our examination of the wage indexing model is presented in section 3 . It is well known that optimal wage indexation depends on the stochastic structure of the underlying economy, and a contribution of Flood and Marion (1982) was to demonstrate that the degree of wage indexation would not be invariant to the country's choice of exchange-rate regime. In their analysis, different permanent exchange rate reglmes lead to different optimal wage indexing polices, and each policy is a fixed function of the time invariant stochastic structure of the economy. In this paper we discuss fixed exchange rate regimes which may collapse, and we find that the optimal degree of wage indexation is state dependent and thus time varying even though the stochastic structure of the economy is time invariant. 


$$
-5-
$$

Our results are presented in the next two sections. For each type of model we first examine permanent exchange rate regimes turning then to a characterization of the economy when a fixed exchange rate regime may possibly collapse. In each model we take the domestic credit component of the money supply to be an exogenous process. This creates an inherent tension between the two government policies, the domestic credit process and the fixed exchange rate regime, which is resolved by the collapse of the regime. This appears to capture the actual priorities of governments without modeling the objective function of the monetary and fiscal authorities. Presumably, one reason why the domestic credit process has priority is because of the seignorage gained by the government from printing money. 2

Because algebraic complexity quickly renders complex versions of each type of model analytically intractable, we worked with simple stripped down versions of each type of model while attempting to retain the essential economic aspects of the problems. Some of the derivations of various results are presented in a techical appendix to facilitate presentation of the results.

\section{A. A DORMBUSCH-TYPE MODEL}

The original Dornbusch (1976) model depicted a medium-size open economy that was large in the market for goods produced at home and small in world asset markets. The cruclal feature of the model was that domestic currency prices of domestic goods were predetermined while the country's exchange rate and other asset prices were currently determined and free to respond to all current shocks. This feature gave rise to the famous overshooting result. Since home goods prices were predetermined, the immediate response of the exchange rate to a money-market disturbance had to be larger than that response would have been had all prices been free to adjust. We use a version of the model that makes output demand determined. It consists of the following relations: 


\section{Glossary of Variables for Model I}

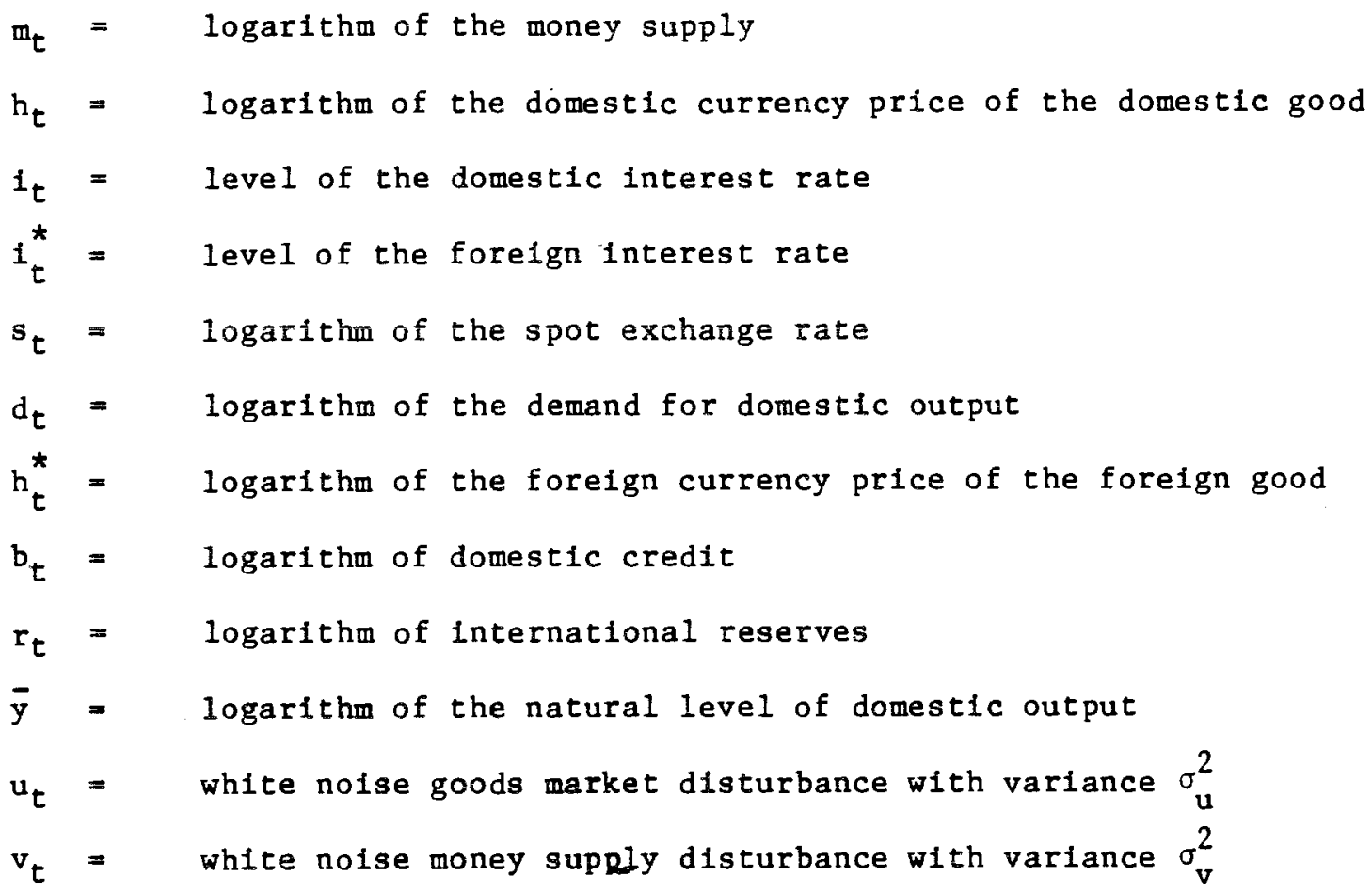

Equations of Model I

Money Market Equilibrium

$$
m_{t}-h_{t}=-a 1_{t}+\gamma d_{t}, \alpha>0, \gamma>0
$$

Capital Market Equilbrium

$$
i_{t}=i_{t}^{*}+E_{t} s_{t+1}-s_{t}
$$

Goods Market Demand

$$
d_{t}=\beta\left(h_{t}^{*}+s_{t}-h_{t}\right)+u_{t}
$$


Domestic Price Determination

$$
B\left(h_{t}^{*}+E_{t-1} s_{t}-h_{t}\right)+E_{t-1}{ }_{t}=\bar{y}
$$

Money Supply Definition

$$
m_{t}=\omega b_{t}+(1-\omega) r_{t}, \quad 0<\omega<1
$$

Domestic Credit Process

$$
b_{t}=\mu+b_{t-1}+v_{t}
$$

Equation (1) is money market equilibrium. The logarithm of the real money supply, $m_{t}-h_{t}$, equals the demand for real money balances, $-\alpha f_{t}+\gamma d_{t} \cdot{ }^{3}$ The demand for money depends negatively on the opportunity cost of holding money, the nominal interest rate, and it depends positively on the real demand for home goods, $d_{t}$. The equilibrium condition for the world capttal market is given in equation (2) by the uncovered interest rate parity condition. The demand for domestic output is specified in equation (3). Demand for home goods depends negatively on the logarithm of the relative price of home goods in terms of foreign goods, $h_{t}-\left(h_{t}^{*}+s_{t}\right)$, and $u_{t}$ is a stochastic demand disturbance. Equation (4) states that $h_{t}$ is set at time $t-1$ at the level that is expected to clear the market for domestic goods by equating expected demand to full employment output, $\bar{y}$. Actual output in period $t$ is determined by the demand for it given the predetermined variables $h_{t}$ and $h_{t}^{*}$. The composition of the money supply is given by equation (5). The nominal monoy supply is composed of a domestic credit component and an international reserves component. Equation (6) states that the rate of growth of domestic credit, 
$b_{t}-b_{t-1}$, is a constant $\mu$ plus a stochastic term, $v_{t} \cdot$

$E_{t-j} x_{t}$ is the mathematical expectation of $x_{t}$ conditional on information from date $t-j, j=0,1$. It is assumed that $u_{t}$ and $v_{t}$ are mutually and serially uncorrelated with $E_{t-1} u_{t}=E_{t-1} v_{t}=0$ and with constant variances $\sigma_{u}^{2}$ and $\sigma_{v}^{2}$. The foreign price and foreign interest rate are also exogenous stochastic processes. We assume that $h_{t}^{*}=h_{t-1}^{*}+z_{t-1}^{*}$ where $z_{t-1}^{*}$ is serially uncorrelated and uncorrelated with the model's other disturbances. Its variance is $\sigma_{z^{*}}^{2}$, and it is an element of the time $t-1$ information set. This dating convention recognizes that foreign price setters are also setting prices for period $t$ at time $t-1$. The foreign nominal interest rate, $i_{t}^{*}=i^{*}+$ $x_{t}^{*}$ is assumed to be serially uncorrelated with mean $i^{*}$. The innovation in the foreign interest rate, $x_{t}^{*}$, is assumed to be orthogonal to the other stochastic processes and to have a constant variance $\sigma_{x^{*}}^{2}$

Our comparison of alternative exchange rate regimes focuses on the variability of real output. For the permanent regimes we measure variability with the conditional variance $v_{t-1}\left(y_{t}\right)=E_{t-1}\left(y_{t}-E_{t-1} y_{t}\right)^{2}$. For the collapsing fixed rate regime we use this measure as well as an alternative. In all regimes $\bar{y}=E_{t-1} d_{t}$, and in order to simplify the presentation, we normalized $\bar{y}=E_{t-1} d_{t}=0$. Consequently, the conditional variance of output is

$$
E_{t-1}\left(d_{t}^{2}\right)=B^{2} v_{t-1}\left(s_{t}\right)+\sigma_{u}^{2}+2 B C_{t-1}\left(s_{t} ; u_{t}\right)
$$

where $C_{t-1}(\cdot ; \cdot)$ denotes the conditional covariance nperator. 


\section{B. SOLUTIONS FOR PERMANENT EXCHANGE RATB REGIMES}

When exchange rates are perfectly flexible, there is no intervention in the forelgn exchange market implying that $r_{t}$ is the constant $\bar{r}$. A solution for the exchange rate can be found by recognizing that the variables on the right-hand side of (8) completely describe the current state of the system. Consequently, the linearity of the model allows us to apply the method of undetermined coefficients, and we find

$$
s_{t}=\lambda_{0}+\lambda_{1} h_{t}^{*}+\lambda_{2} b_{t-1}+\lambda_{3} x_{t}^{*}+\lambda_{4} z_{t}^{*}+\lambda_{5} v_{t}+\lambda_{6} u_{t}
$$

where

$$
\begin{aligned}
& \lambda_{0}=(1+\alpha) \omega \mu+(1-\omega) \bar{r}+\alpha i^{*} \\
& \lambda_{1}=-1 \\
& \lambda_{2}=\omega \\
& \lambda_{3}=\alpha /(\alpha+\gamma \beta) \\
& \lambda_{4}=-\alpha /(\alpha+\gamma \beta) \\
& \lambda_{5}=(1+\alpha) \omega /(\alpha+\gamma \beta) \\
& \lambda_{6}=-\gamma /(\alpha+\gamma \beta) .
\end{aligned}
$$


From (7) and (8), the conditional variance of real output under a pure flexible exchange rate regime is

$$
v_{t-1}\left(y_{t}\right) \mid F l e x=\beta^{2}\left(\lambda_{3}^{2} \sigma_{x^{*}}^{2}+\lambda_{4}^{2} \sigma_{z^{*}}^{2}+\lambda_{5}^{2} \sigma_{v}^{2}+\lambda_{6}^{2} \sigma_{u}^{2}\right)+\sigma_{u}^{2}+2 \beta \lambda{ }_{6} \sigma_{u}^{2} .
$$

If the exchange rate is permanently fixed at a level $\bar{s}$ and the government runs an exogenous domestic credit process, then $r_{t}$ becomes endogenous. International reserves adjust during the period to equate the demand for money and the supply of money. Under a permanently fixed exchange rate regime, $s_{t}=$ $\bar{s}$ for all $t$, and the conditional variance of output is simply

$$
v_{t-1}\left(y_{t}\right) \mid F i x_{u}=\sigma_{u}^{2}
$$

By comparing (9) and (10), one sees that the conditional variance of real output under a flexible exchange rate regime exceeds the conditional variance of real output under a fixed rate regime whenever

$$
\beta\left[\alpha^{2}\left(\sigma_{x^{*}}^{2}+\sigma_{z^{*}}^{2}\right)+(1+\alpha)^{2} \omega^{2} \sigma_{v}^{2}\right]>(2 \alpha+\gamma \beta) \gamma \sigma_{u}^{2}
$$

Because the flexible exchange rate regime allows foreign price and interest rate disturbances and the domestic money supply disturbance to affect the exchange rate thereby altering the terms of trade, these disturbances add additional variance to the demand for and supply of real output under such a regime. A counterbalancing effect that tends to reduce the volatility of real output under flexible rates when compared to fixed rates is that positive real demand shocks appreciate the domestic currency thereby improving the terms of trade, and this change in relative prices reduces the demand for real output. The appreciation of the currency arises because the increase in real 
demand increases the demand for money. The smaller is the elastictty of the demand for money with respect to real output, $Y$, the more 11 kely is the volatility of real output to be greater under flexible exchange rates than under fixed rates. In order to provide a striking comparison in what follows, we assume that $\gamma=0$. With this change, permanently flextble rates produce an unambiguously larger volatility of real output than permanently fixed exchange rates.

\section{C. SOLUTION FOR A TEMPORARY FIXED EXCHANGE RATE REGIME}

Our fixed exchange rate solution from the previous section ignored the possibility that the economy may evolve into a state where it is worthwhile for agents to attack the government's foreign exchange reserves and end the fixed rate regime. 4 We assume that the monetary authority will defend the fixed rate regime only until its reserves hit some known lower bound, $\tilde{r}$. After reserves hit this bound, the monetary authority is assumed to abandon the fixed-rate regime forever. If agents successfully attack the fixed-rate regime, they produce the floating rate whose level is given by

$$
\tilde{s}_{t}=\tilde{\lambda}_{0}+\lambda_{1} \mathrm{~h}_{t}^{*}+\lambda_{2} \mathrm{~b}_{t-1}+\lambda_{3} \mathrm{x}_{t}^{*}+\lambda_{4} z_{t}^{*}+\lambda_{5} \mathrm{v}_{t}
$$

where $\tilde{\lambda}_{0} \equiv \cdot\left[(1-\omega) \tilde{r}+\alpha{ }^{*}+(1+\alpha) \omega \mu\right]$, and $\lambda_{1}$ through $\lambda_{5}$ are as above except with $\gamma=0$. If $\tilde{s}_{t}>\bar{s}$, risk-free profits can be had at the expense of the monetary authority. If $\tilde{s}_{t}<\bar{s}$, attackers would make losses and consequently would not attack. If an a'tack took place when $\tilde{s}_{t}=\bar{s}$, no profits would be realized, and the post-attack exchange rate would be $\bar{s}$. Thus, we treat this case as part of the no attack situation without loss of generality, and an attack takes place if and only if $\tilde{s}_{t}>\bar{s} .5$ 
At time $t-1$, when setting nominal prices for period $t$, agents realize that the fixed exchange rate regime could collapse next period. Therefore, the conditional expectation of the exchange rate in period $t$ is not simply $\bar{s}$, but it is the probability weighted average of the conditional expectations under the two possible regimes:

$$
E_{t-1} s_{t}=\left(1-\pi_{t-1}\right) \bar{s}+\pi_{t-1} E_{t-1}\left(\tilde{s}_{t} \mid C_{t}\right),
$$

where $\pi_{t-1}$ is the probability at time $t-1$ of an attack at time $t$ and $E_{t-1}\left(\tilde{s}_{t} \mid c_{t}\right)$ is the expectation at $t-1$ of $\tilde{s}_{t}$ conditional on a collapse at time $t$.

The probability of an attack next period, is $\pi_{t-1}=\operatorname{pr}_{t-1}\left\{\tilde{s}_{t}-\bar{s}>0\right\}$ where $\operatorname{pr}_{t-1}\{x\}$ is the probability of event $x$ given the $t-1$ information set. Examination of the solution for the flexible exchange rate in (12) indicates that the probability of an attack can be stated as $\pi_{t-1}=p r_{t-1}\left\{\varepsilon_{t}>\delta_{t-1}\right\}$ where $\varepsilon_{t}=\lambda_{3} x_{t}^{*}+\lambda_{4} z_{t}^{*}+\lambda_{5} v_{t}$ is the innovation in the shadow flexible exchange rate that becomes the actual flexible rate if there is a collapse of the fixed rate regime at time $t$, and $\delta_{t-1}=\bar{s}-\tilde{\lambda}_{0}-\lambda_{1} h_{t}^{*}-\lambda_{2} b_{t-1}$ is the amount by which the fixed exchange rate exceeds the conditional expectation of $\tilde{s}_{t}$ based on time $t-1$ information. As $\delta_{t-1}$ falls, the probability of collapse increases monotonically since a larger part of the distribution of $\varepsilon_{t}$ can induce a collapse.

The volatility of real output under a fixed exchange rate regime that may collapse is

$$
v_{t-1}\left(y_{t}\right) / C . F 1 x=B^{2} E_{t-1}\left(s_{t}-E_{t-1} s_{t}\right)^{2}+\sigma_{u}^{2}
$$


which is clearly larger than $v_{t-1}\left(y_{t}\right) \mid F i x^{*}$ It is also true that

$\mathrm{V}_{t-1}\left(\mathrm{y}_{t}\right) \mid \mathrm{C} . \mathrm{Fix}$ is less than $\mathrm{V}_{t-1}\left(\mathrm{y}_{t}\right) \mid \mathrm{Flex}$. In order to determine this result, consider the following decomposition of the conditlonal variance of the exchange rate under the two regimes:

$$
\begin{gathered}
\left.v_{t-1}\left(s_{t}\right) \mid C \cdot F 1 x=\left(1-\pi_{t-1}\right)\right)^{-2}+\pi_{t-1} E_{t-1}\left(\tilde{s}_{t}^{2} \mid C_{t}\right) \\
=\left[\left(1-\pi_{t-1}\right) \bar{s}+\pi_{t-1} E_{t-1}\left(\tilde{s}_{t} \mid C_{t}\right)\right]^{2} \\
v_{t-1}\left(s_{t}\right) \mid F 1 e x=\left(1-\pi_{t-1}\right) E_{t-1}\left(\tilde{s}_{t}^{2} \mid N C_{t}\right)+\pi_{t-1} E_{t-1}\left(\tilde{s}_{t}^{2} \mid C_{t}\right) \\
-\left[\left(1-\pi_{t-1}\right) E_{t-1}\left(\tilde{s}_{t} \mid N C_{t}\right)+\pi_{t-1} E_{t-1}\left(\tilde{s}_{t} \mid C_{t}\right)\right]^{2}
\end{gathered}
$$

Expressions (15a) and (15b) ut1lize-the facts that the unconditional moment of a distribution is the probability weighted sum of the conditional moments and that the exchange rate does not collapse $\left(N C_{t}\right)$ when $\varepsilon_{t} \leqslant \delta_{t-1}$. In the Appendix we demonstrate that subtracting (15a) from (15b) and rearranging terms gives

$$
\begin{aligned}
& \left(1-\pi_{t-1}\right) V_{t-1}\left(s_{t} \mid N C_{t}\right)+\pi_{t-1}\left(1-\pi_{t-1}\right)\left\{\left[\bar{s}-E_{t-1}\left(\tilde{s}_{t} \mid N C_{t}\right)\right]^{2}+\right. \\
& \left.2\left[\bar{s}-E_{t-1}\left(\tilde{s}_{t} \mid N C_{t}\right)\right]\left[E_{t-1}\left(\tilde{s}_{t} \mid C_{t}\right)-\bar{s}\right]\right\}
\end{aligned}
$$

which is unambiguously positive since $E_{t-1}\left(\tilde{s}_{t} \mid C_{t}\right)>\bar{s}>E_{t-1}\left(\tilde{s}_{t} \mid N C C_{t}\right)$. This demonstrates that a regime of collapsing fixed rates has a more volatile real 
output than a regime of permanently fixed rates, but the volatility is not larger than under a pure flexible rate regime.

These results are not particularly surprising since as $\delta_{t-1}$ increases, the probability of an attack decreases, and the conditional variance of output approaches that under a fixed exchange rate regime. Similarly, as $\delta_{t-1}$ decreases, the probability of an attack increases, and the conditional variance of real output approaches that under a flexible exchange rate regime. For intermediate values of $\delta_{t-1}$, the conditional variance is between the two extreme regimes.

The conditional variance used in the above comparisons takes into account the forecast errors that arise from both parts of the distributions of $\varepsilon_{t}$ which we have denoted $C_{t}\left(\varepsilon_{t}>\delta_{t-1}\right)$ and $N C_{t}\left(\varepsilon_{t}<\delta_{t-1}\right)$. An alternative way to examine the volatility of output under a potentially collapsing fixed exchange rate regime is to estimate the varfance of output by examining only the realizations of output under a gime that could collapse but had not collapsed during the sample. This corresponds to the sample variance that one would measure by using all the data during a regime of fixed rates up to the point of a collapse.

The volatility of real output in this case is denoted

$$
V_{t-1}\left(y_{t}\right) \mid C . F i x .2=\beta^{2}\left(\bar{s}-E_{t-1} s_{t}\right)^{2}+\sigma_{u}^{2} .
$$

In order to conduct an analytical comparison of (17) and (15b), it is ne essary to consider an actual probability distribution for $\varepsilon_{t}{ }^{*}$ Analytical tractablity also rules out obvious candidates like the normal distribution, but the point of the analysis is to demonstrate that the squared exchange rate forecast error in (17) can be greater than the one in (15b) for some 
distributions. Consequently, we examined the model under the hypotheses that $\varepsilon_{t}$ had either a uniform distribution or a double exponential probability distribution. Only the results for the uniform distribution are reported in the text.

When $\varepsilon_{t}$ is uniformly distributed, we have

$$
\begin{array}{ll}
f\left(\varepsilon_{t}\right)=1 / 2 n, & -\eta<\varepsilon_{t}<n \\
f\left(\varepsilon_{t}\right)=0, & \text { elsewhere, }
\end{array}
$$

where $f\left(\varepsilon_{t}\right)$ is the probability density function for the random variable $\varepsilon_{t}$. The unconditional expected value of $\varepsilon$ is zero and its unconditional variance is $n^{2} / 3$. It also follows that

$$
\pi_{t-1}=\left(n-\delta_{t-1}\right) / 2 n, \quad--n<\delta_{t-1}<n
$$

In the following discussion we will assume $-n<\delta_{t-1}<n$, since this is the region of interest. If $\delta_{t-1}>n, \pi_{t-1}=0$, and $\delta_{t-1}$ cannot be less than - $n$, since this would make $\pi_{t-1}=1$ and would cause the collapse in period $t-1$.

In the Appendix we use (7) and (18) to find the conditional variance of output during a fixed-rate regime which may collapse. This expression is

$$
\begin{gathered}
V_{t-1}\left(y_{t}\right) \mid C . F 1 x=\beta^{2}\left[-\left(n-\delta_{t-1}\right)^{4} / 16 n^{2}+\left(n^{3}-\delta_{t-1}^{3}\right) / 6 n\right] \\
-B^{2}\left[\delta_{t-1}\left(n-\delta_{t-1}\right) / 2\right]+\sigma_{u}^{2}
\end{gathered}
$$


We also use (7) and (18) to find the conditional variance of output during a permanently floating exchange rate regime. This expression is

$$
v_{t-1}\left(y_{t}\right) \mid \text { Flex }=\beta^{2} \eta^{2} / 3+\sigma_{u}^{2} \text {. }
$$

In Figure 1, (20a) and (20b) are plotted against $\delta_{t-1}$. Expression (20b) is independent of $\delta_{t-1}$, and $i t$ is the upper limit of $(20 a)$ as $\delta_{t-1}+-n$. The lower limit of $(20 \mathrm{~b})$ as $\delta_{t-1}+\eta$ is $\sigma_{u}^{2}$, which is output variance for a fixed rate regime without collapse. These results confirm what was found earlier for arbitrary probability distributions. When $\delta_{t-1}=n$, an attack next period is unprofitable with probability one, so output variance is $\sigma_{\mathrm{u}}^{2}$. When $\delta_{t-1}=-\eta$, an attack next period happens with probability one, so output variance is $\left[\beta^{2} \eta^{2} / 3\right]+\sigma_{u}^{2}$. For values of $\delta_{t-1}$ between $\eta$ and $-\eta$, output variance is a convex combination of the two extremes with weights that vary nonlinearly with $\delta_{t-1}$.

In our examination of these results, however, we asked what would happen to measured output variance during the fixed-rate regime as $\delta$ changed but the regime did not collapse. The Appendix demonstrates that output variance during the fixed-rate regime would be given by

$$
v_{t-1}\left(y_{t}\right) / C . F i x .2=B^{2}\left(\eta-\delta_{t-1}\right)^{4} / 16 \eta^{2}+\sigma_{u}^{2}
$$

This quantity also depends on $\delta_{t-1}$ and is plotted in Figure 1 . The interesting feature of this line is that the maximum variance for output is above output variance for a permanent float. Indeed, the volatilities in $(20 b)$ and $(20 c)$ are equal when $\delta_{t-1}=-\left[(16 / 3)^{1 / 4}-1\right] n=-.52 n$. The implication of this relationship is that while $\delta_{t-1}$ is in the range below 
$-.52 n$, measured output variance under the fixed exchange rate regime is larger than output variance would be under a floating exchange rate regime.

This result is due entirely to the fact that exchange rate prediction errors can be larger, for some ranges of $\delta$, for a fixed-rate regime which might collapse but does not than for a floating-rate regime. In our example with exchange rate innovations drawn from a unfform distribution, this occurs

whenever $\delta_{t-1}<-.52 n$. The lower is $\delta_{t-1}$, the more likely is a collapse of the regime, but if actual draws of $\varepsilon$ are not greater than $\delta_{t-1}$, the regime remalns viable and output variance is larger than under flexible rates.

\section{A. A FLOOD-MARION TYPE MODEL}

One version of the Flood-Marion (1982) model depicted an open economy that was small both in the market for goods and in the market for assets. Wage contracts were set one period in advance of the realizations of disturbances. Wages, however, were-Indexed to the price level in a manner to minimize the deadweight loss from wages being different than their level in a frictionless (no contract) economy. ${ }^{6}$ The major result of Flood and Marion was that the degree of wage indexation depended on the choice of exchange-rate regime. They found that a small open economy would index wages fully under a regime of permanently fixed exchange rates, but wages would only be indexed partially under a regime of floating exchange rates. Their results indicated. that the degree of wage indexing would remain constant under any single regime as long as the underlying stochastic structure of the economy was constant. In our version of the Flood-Marion model, the fixed exchange rate regime may collapse. Hence, wages are not fully indexed for such a regime, and the degree of indexation is time varying even though the underlying exogenous stochastic structure is time invariant. 
We demonstrate this result in a stripped-down version of the Flood-Marion model consisting of the following relations:

\section{Glossary of Variables for Model II}

$\mathrm{m}_{\mathrm{t}} \quad=$ logarithm of the money supply

$p_{t}=$ logarithm of the price level

$b_{t}=$ logarithm of domestic credit (assumed constant)

$r_{t}=$ logarithm of international reserves

$P_{t}^{*} \quad=$ logarithm of the foreign price level

$s_{t}=$ logarithm of the exchange rate

$y_{t}=$ logarithm of domestic output

$\hat{y}_{t}=$ logarithm of the benchmark level of domestic output

$u_{t}=$ domestic real disturbance with variance $\sigma_{u}^{2}$

$v_{t}^{*} \quad=$ foreign price disturbance with variance $\sigma_{v}^{2}$

Equations of Model II

Money Market Equilibrium

$$
m_{t}-p_{t}=\alpha+u_{t}
$$

Law of One Price

$$
p_{t}=p_{t}^{*}+s_{t}
$$

\section{Aggregate Supply}

$$
y_{t}=\bar{y}+z\left(p_{t}-E_{t-1} p_{t}\right)+u_{t}
$$

Benchmark Output

$$
\hat{y}_{t}=\bar{y}+\rho u_{t}, \quad 0<\rho<1
$$


Money Supply Defintion

$$
m_{t}=\omega \bar{b}+(1-\omega) r_{t}
$$

\section{Foreign Price Process}

$$
p_{t}^{*}=p_{t-1}^{*}+v_{t}^{*}
$$

Equation (21) states that the supply of real money balances, $m_{t}-p_{t}$, is equal to the demand for them, $\alpha+u_{t^{*}}$ To make the model analytically tractable, we simplified the money demand function, removing from the FloodMarion model the opportunity cost of holding money as well as the portion of output that is responsive to prices. Money demand thus depends only on a constant, $a$, and the productivity disturbance, $u_{t}$. The qualitative properties of our results do not depend on these simplifications, but they enormously simplify some later calculations. Equation (22) gives the goods arbitrage condition, which is equivalent to purchasing power parity in this one-good model. Equation (23), which is derived in the Appendix of Flood and Marton, is the aggregate supply function. The variable $z$ is proportional to one minus the optimal degree to which the nominal wage is indexed to the price level. Since $z$ is a deterministic linear function of the degree of indexing, the optimal wage contract may be found by minimizing the loss function (given below) with respect to $z$. Equation (24), which is also derived in the Appendix of Flood and Marion, gives the frictionless benchmark (no indexing) level of output, $\hat{y}_{t^{*}}$ Equation (25) specifies that the money supply is composed of domestic credit, which we hold constant, and international reserves. As spectfied 1 in equation (26), the foreign price follows a random walk. The disturbance terms, $u_{t}$ and $v_{t}^{*}$ have zero unconditional means and are mutually and serially uncorrelated. 
As in Flood and Marion, it is assumed that wage contracts are set according to

$$
\min _{z} E_{t-1}\left(y_{t}-\hat{y}_{t}\right)^{2}
$$

where $E_{t-1} x_{t}$ is the mathematical expectation of $x_{t}$ conditional on information from time $t-1$, which includes all variables dated $t-1$ and earlier as well as the structure of the model. The problem posed in (27) is to minimize a quadratic measure of deadweight loss by an appropriate choice of $z$. By substituting from (23) and (24), the optimal indexing problem (27) may be rewritten as

$$
\min _{z} E_{t-1}\left[z\left(p_{t}-E_{t-1} p_{t}\right)+\lambda u_{t}\right]^{2}
$$

where $0<\lambda=1-\rho<1$. The solution to (28) denoted $z_{t-1}$ to reflect the possibility that it may depend on time $t-1$ information is

$$
z_{t-1}=-\lambda C_{t-1}\left(p_{t} ; u_{t}\right) / v_{t-1}\left(p_{t}\right)
$$

where $C_{t-1}(\cdot ; \cdot)$ denotes the conditional covariance and $V_{t-1}(\cdot)$ denotes the conditional variance.

\section{B. SOLUTIONS FOR PERMANENT EXCHANGE RATE REGIMES}

When the exchange rate is flexible, there is no intervention in tue foreign exchange market. Thus, international reserves, $r_{t}$, are constant at the level $\bar{r}$, and the exchange rate is $s_{t}=\bar{m}-\alpha-u_{t}-p_{t}^{*}$, where $\vec{m} \equiv \omega \bar{b}+(1-\omega) \bar{r}$. The domestic price prediction error, 
$P_{t}-E_{t-1} P_{t}$, equals $v_{t}^{*}+s_{t}-E_{t-1} s_{t}$, which is equal to $-u_{t}$. Hence, the optimal value of $z$ is $z_{\mid \text {Flex }}=\lambda$, and this value of $z$ will set the loss function to zero. This special result is due to the assumed absence of Independent disturbances to the money supply or to money demand in this simplified version of the model. In general, the optimal $z$ will depend on the relative sizes of the variances of the various shocks (see Flood and Marion, p. 54). Presently, the important point is that $z /$ Flex is positive and time invariant.

When the exchange rate is permanently fixed, $r_{t}$ becomes demand determined, and the domestic price is given by $p_{t}=p_{t}^{*}+\bar{s}$, where $\bar{s}$ is the fixed exchange rate. In this circumstance the domestic price prediction error, $p_{t}-E_{t-1} p_{t}$, is simply the prediction error of foreign prices, $v_{t}^{*}$. Consequently, since $v_{t}^{*}$ and $u_{t}$ are uncorrelated, the solution to (29) is to set $z_{\mid F i x}=0$ to screen forelgn price disturances out of the domestic loss function. This is exactly the result in Flood and Marion.

\section{C. SOLUTION FOR A TEMPORARY FLXED EXCHANGE RATE REGIME}

The fixed-rate solution in the previous section presumed that the fixedrate regime would last forever. As before, however, for some configurations of the state variables of the economy it may be profitable for agents to attack the government's stock of forelgn exchange reserves and end the fixedrate regime. We continue to assume that the monetary authority will defend the fixed rate only untfl international reserves hit some known lower bound, $\tilde{r}$, and that after hitting this bound, the fixed-rate regime will be abandoned forever in favor of a flexible exchange rate regime. In this model, if agents attack the fixed rate, they will produce the floating rate given by 


$$
\tilde{s}_{t}=\tilde{m}-p_{t}^{*}-\alpha-u_{t},
$$

where $\tilde{m} \equiv \omega \bar{b}+(1-\omega) \tilde{r}$. Thus, when forming wage contracts based on information available at time $t-1$, the contracting parties must plan for the possibility that the fixed-rate regime will be attacked successfully at time t. The probability of an attack taking place at $t$, based on $t-1$ information, is $\pi_{t-1}=p r_{t-1}\left\{\tilde{s}_{t}-\bar{s}>0\right\}$, or $\pi_{t-1}=\operatorname{pr}_{t-1}\left\{\left(u_{t}+v_{t}^{*}\right)<\gamma_{t-1}\right\}$, where $\gamma_{t-1} \equiv\left(\tilde{m}-p_{t-1}^{*}-a-\bar{s}\right)$.

As before, when there is a possibility that the exchange rate regime will collapse, the agents take account of the possibility in determining their contractual relations. In this case, the optimal degree of indexing depends on the probability of the collapse because this affects the unconditional time $t-1$ covariance and variance in (29).

As is shown in the Appendix, the solution to (29) for this case is

$$
z_{t-1}=\frac{-\pi_{t-1} \lambda E_{t-1}\left[u_{t}\left(\tilde{s}_{t}-\bar{s}\right) \mid C_{t}\right]}{\sigma_{v *}^{2}+\pi_{t-1} E_{t-1}\left[\left(\tilde{s}_{t}-\bar{s}\right)^{2} \mid C_{t}\right]+\pi_{t-1}^{2}\left[\bar{s}-E_{t-1}\left(\tilde{s}_{t} \mid C_{t}\right)\right]^{2}+2 \pi_{t-1} E_{t-1}\left[\left(\tilde{s}_{t}-\bar{s}\right) v_{t}^{*} \mid C_{t}\right]}
$$

where $\sigma^{2}{ }^{*}$ is the unconditional variance of $v_{t}^{*}$, and $E_{t-1}\left(\cdot \mid c_{t}\right)$ is the expectation operator based on time $t-1$ information but conditional on a collapse taking place at t. The expression on the right hand side of (31), although complicated, is simply the covariance of $\lambda u_{t}$ and $p_{t}$ conditional only on $t-1$ information divided by the variance of $p_{t}$ conditional only on $t-1$ information.

In typical wage indexing models the optimal $z$ is a time invariant function of the variances and covarfances of the underlying disturbances. Our main point in this section is that it will not in general be time invariant 
when stochastic process switching is possible. This point can be seen at an intuitive level by examining ( 31 ) and noticing that $z_{t-1}$ depends on $\pi_{t-1}$, the state dependent probability at $t-1$ of an attack at $t$.

To make additional progress concerning $z_{t-1}$, we again made specific assumptions about the probability distribution functions for $v_{t}^{*}$ and $u_{t}$. In the Appendix we assume that the orthogonal disturbances $v_{t}^{*}$ and $u_{t}$ are each uniformly distributed on the interval $[-\eta, \eta]$. This assumption leads to the closed form but complicated expression for $z_{t-1}$ shown in the Appendix. Since the final expression for $z_{t-1}$ is so complicated, we simulated it for a few values of $\gamma_{t-1}$ in the interval $[-2 \eta, 0]$, and we set $\eta=1$. In this situation we found:

$$
\begin{aligned}
& \lim _{t-1}+-2 z_{t-1}=0 \\
& \gamma_{t-1}=-1 \Rightarrow z_{t-1}=(.107) \lambda \\
& \gamma_{t-1}=0 \Rightarrow z_{t-1}=(3 / 8) \lambda .
\end{aligned}
$$

Example (32a) is the Flood-Marion result; when $\gamma_{t-1}+-2$, it is impossible for $v_{t}^{*}+u_{t}$ to be less than $\gamma_{t-1}$. Consequently, $\pi_{t-1} \rightarrow 0$, and an attack on the fixed-rate regime at time $t$ is impossible because it cannot be profitable. It is thus optimal to set $z_{t-1}=0$ (index wages fully), thereby screening all foreign disturbances out of the loss function. For larger values of $Y_{t-1}$, such as -1 and 0 in examples $(32 b)$ and (32c), an attack is possible and contracts written at $t-1$ allow for this contingency by setting $z_{t-1}$ at optimal values between 0 , the optimal value for a fixed exchange rate with no attack possible, and $\lambda$, the optimal value for a permanently floating exchange rate. 
The point of this simple example is to note that an economy's optimal choice of wage indexation to the price level may not depend simply on the polfcy currently being pursued by the government and the constant covariance structure of exogenous disturbances. It may also depend on agents' rational beliefs about the possibility of switches in government policies in the future. Consequently, the observation that indexing in wage contracts is time varying need not necessarily be associated with variation in the conditional covariance matrix of the underlying exogenous disturbances, it may instead be associated with time varlation in agents' beliefs concerning the permanance of currently implemented policies. 7

\section{CONCLUSIONS}

The purpose of this paper was to examine how some aspects of the real economy, such as the determination of output, relative prices and real wages, are influenced by the potential collapse of a fixed exchange rate regime. We examined the implications of the potential switch in government policies in simple versions of two popular international macroeconomic models. In both models, agents must take an action that predetermines some nominal variable. Consequently, monetary policy and the choice of exchange rate regime have real effects. In both models the monetary authorfty is only willing to defend its exchange rate until its reserves hit a known lower bound. In each case the monetary authorfty also conducts an exogenous domestic credit policy. If the authorities were willing to conduct an endogenous domestic credit policy, there would be no need for internatioual reserves, and the probability of collapse of the fixed exchange rate regime would be zero.

Clearly, one interesting area for future work is the linkage of the domestic credit policy and the constraints imposed by the government budget 
constraint with the choice of exchange rate regime. Eaton (1984) has investigated this problem in a neoclassical context with exogenous real output.

Another interesting area for future work is to focus on devaluations as opposed to the switch from fixed to flexible rates investigated here. What determines the timing and magnitude of a devaluation? Blanco and Garber (1984) have begun such an investigation. 
$-26-$

APPEND IX

Al. RESULTS FOR SECTION 2

This Appendix provides the derivation of some results in Section 2. The first result involves a comparison of the conditional variance of the exchange rate under flexible rates in ( $15 \mathrm{~b})$ and under collapsing fixed rates in (15a). These equations are reproduced here as (A1) and (A2) respectively:

$$
\begin{gathered}
V_{t-1}\left(s_{t}\right) \mid F \text { Flex }=\left(1-\pi_{t-1}\right) E_{t-1}\left(\tilde{s}_{t}^{2} \mid N C_{t}\right)+\pi_{t-1} E_{t-1}\left(\tilde{s}_{t}^{2} \mid C_{t}\right) \\
-\left[\left(1-\pi_{t-1}\right) E_{t-1}\left(\tilde{s}_{t} \mid N C_{t}\right)+\pi_{t-1} E_{t-1}\left(\tilde{s}_{t} \mid C_{t}\right)\right]^{2} \\
V_{t-1}\left(s_{t}\right) \mid C \cdot F 1 x=\left(1-\pi_{t-1}\right) \bar{s}^{-2}+\pi_{t-1} E_{t-1}\left(\tilde{s}_{t}^{2} \mid C_{t}\right) \\
-\left[\left(1-\pi_{t-1}\right) \bar{s}+\pi_{t-1} E_{t-1}\left(\tilde{s}_{t} \mid C_{t}\right)\right]^{2} .
\end{gathered}
$$

Subtracting (A2) from (A1) gives

$$
\begin{aligned}
(1- & \left.\pi_{t-1}\right)\left[E_{t-1}\left(\tilde{s}_{t}^{2} \mid N C_{t}\right)-\bar{s}^{2}\right]-\left(1-\pi_{t-1}\right)^{2}\left\{\left[E_{t-1}\left(\tilde{s}_{t} \mid N C_{t}\right)\right]^{2}-\bar{s}^{2}\right\} \\
& -2\left(1-\pi_{t-1}\right) \pi_{t-1}\left[E_{t-1}\left(\tilde{s}_{t} \mid N C_{t}\right)-\bar{s}_{t-1}\left(\tilde{s}_{t} \mid C_{t}\right)\right. \\
& =\left(1-\pi_{t-1}\right)\left[E_{t-1}\left(\tilde{s}_{t}^{2} \mid N C_{t}\right)-\left[E_{t-1}\left(\tilde{s}_{t} \mid N C_{t}\right)\right]^{2}\right\}+ \\
& \pi_{t-1}\left(1-\pi_{t-1}\right)\left\{\left[E_{t-1}\left(\tilde{s}_{t} \mid N C_{t}\right)\right]^{2}-\bar{s}^{2}-2\left[E_{t-1}\left(s_{t} \mid N C_{t}\right)-\bar{s}_{t-1}\left(\tilde{s}_{t} \mid C_{t}\right)\right\}\right.
\end{aligned}
$$




$$
\begin{aligned}
& =\left(1-\pi_{t-1}\right) V_{t-1}\left(\tilde{s}_{t} \mid N C_{t}\right)+\pi_{t-1}\left(1-\pi_{t-1}\right)\left[\left[\bar{s}-E_{t-1}\left(\tilde{s}_{t} \mid N C_{t}\right)\right]^{2}+\right. \\
& \left.2\left[\bar{s}-E_{t-1}\left(\tilde{s}_{t} \mid N C_{t}\right)\right]\left[E_{t-1}\left(\tilde{s}_{t} \mid C_{t}\right]-s\right]\right\}
\end{aligned}
$$

where $v_{t-1}\left(\tilde{s}_{t} \mid N C_{t}\right)$ is the time $t-1$ conditional variance given no collapse at t. Expression (A3) is (16) in the text, and it is clearly positive since $E_{t-1}\left(\tilde{s}_{t} \mid C_{t}\right)>\bar{s}>E_{t-1}\left(\tilde{s}_{t} \mid N C_{t}\right)$.

The second set of results involves the comparison of measures of the variance of real output under alternative regimes in (20a, b, c) under the hypothesis that the innovation in the exchange rate, $\varepsilon_{t}$, has a uniform probability distribution on the interval $[-n, n]$.

The expression of interest is $E_{t-1}\left(y_{t}-E_{t-1} y_{t}\right)^{2}$. From the model in the text $y_{t}-E_{t-1} y_{t}=\beta\left(s_{t}-E_{t-1} s_{t}\right)+u_{t}$, since $h_{t}$ and $h_{t}^{*}$ are known at $t i m e t-1$. The disturbance $u_{t}$ is uncorrelated with $\tilde{s}_{t}$, and it is trivially uncorrelated with $\bar{s}$. Therefore,

$$
E_{t-1}\left(y_{t}-E_{t-1} y_{t}\right)^{2}=\beta^{2} E_{t-1}\left(s_{t}-E_{t-1} s_{t}\right)^{2}+\sigma_{u}^{2},
$$

where $\sigma_{u}^{2}$ is the unconditonal variance of $u_{t}$. Our problem then is to find

$$
\begin{aligned}
E_{t-1}\left(s_{t}-E_{t-1} s_{t}\right)^{2} & =\left(1-\pi_{t-1}\right) E_{t-1}\left[\left(s_{t}-E_{t-1} s_{t}\right)^{2} \mid N C_{t}\right] \\
& +\pi_{t-1} E_{t-1}\left[\left(s_{t}-E_{t-1} s_{t}\right)^{2} \mid C_{t}\right],
\end{aligned}
$$

where $\pi_{t-1}=\operatorname{pr}\left(\varepsilon_{t}>\delta_{t-1}\right)=\left(n-\delta_{t-1}\right) / 2 n$, and $E_{t-1} s_{t}=\left(1-\pi_{t-1}\right) \bar{s}+$ $\pi_{t-1} E_{t-1}\left(\tilde{s}_{t} \mid C_{t}\right)$. Using this information and recognizing that $N C_{t}$ implies $s_{t}$ $=\bar{s}$ and $C_{t}$ implies $s_{t}=\tilde{s}_{t}$ in $(A 5)$ we derive 
$-28-$

$$
\begin{aligned}
E_{t-1}\left(s_{t}-E_{t-1} s_{t}\right)^{2}= & -\pi_{t-1}^{2}\left[\bar{s}-E_{t-1}\left(\tilde{s}_{t} \mid c_{t}\right)\right]^{2} \\
& +\pi_{t-1} E_{t-1}\left[\left(\tilde{s}_{t}-\bar{s}\right)^{2} \mid c_{t}\right] .
\end{aligned}
$$

In the text $\tilde{s}_{t}$ is given by equation (12). Therefore

$$
E_{t-1}\left[\tilde{s}_{t} \mid C_{t}\right]=\tilde{\lambda}_{0}+\lambda_{1} h_{t}^{*}+\lambda_{2} b_{t-1}+E_{t-1}\left(\varepsilon_{t} \mid C_{t}\right),
$$

where $E_{t-1}\left(\varepsilon_{t} \mid C_{t}\right)=\frac{1}{2}\left[\delta_{t-1}+\eta\right]$ since the collapse takes place if and only if $\varepsilon_{t}>\delta_{t-1}$, and $\varepsilon_{t}$ is uniformly distributed conditional on collapse. Equation (A7) may thus be used to obtain $E_{t-1}\left(\tilde{s}_{t} \mid C_{t}\right)-\bar{s}=\frac{1}{2}\left(n-\delta_{t-1}\right)$, since $\delta_{t-1}=\bar{s}-\tilde{\lambda}_{0}-\lambda_{1} h_{t}^{*}-\lambda_{2} b_{t-1}$ which implies that

$$
\left[E_{t-1}\left(\tilde{s}_{t} \mid C_{t}\right)-\bar{s}\right]^{2}=(1 / 4)\left(\pi-\delta_{t-1}\right)^{2}
$$

The second term in $(A 6)$ contains $E_{t-1}\left[\left(\tilde{s}_{t}-\bar{s}\right)^{2} \mid C_{t}\right]$, which is

$$
\begin{aligned}
& E_{t-1}\left[\left(\varepsilon_{t}-\delta_{t-1}\right)^{2} \mid C_{t}\right]=E_{t-1}\left(\varepsilon_{t}^{2} \mid C_{t}\right)-2 \delta_{t-1} E_{t-1}\left(\varepsilon_{t} \mid C_{t}\right)+\delta_{t-1}^{2} \text {. Since } \\
& E_{t-1}\left(\varepsilon_{t}^{2} \mid C_{t}\right)=\int_{\delta_{t-1}}^{n} \varepsilon_{t}^{2}\left(n-\delta_{t-1}\right)^{-1} d \varepsilon_{t}=\left(n^{3}-\delta_{t-1}^{3}\right) / 3\left(n-\delta_{t-1}\right) \text {, we find } \\
& E_{t-1}\left[\left(\tilde{s}_{t}-\bar{s}\right)^{2} \mid C_{t}\right]=\left[\left(n^{3}-\delta_{t-1}^{3}\right) / 3\left(n-\delta_{t-1}\right)\right]-\delta_{t-1} n .
\end{aligned}
$$

Use (A8) and (A9) in (A6) to obtain

$$
\begin{aligned}
E_{t-1}\left[\left(s_{t}-E_{t-1} s_{t}\right)^{2}\right] & =-\pi_{t-1}^{2}(1 / 4)\left[n-\delta_{t-1}\right]^{2} \\
& +\pi_{t-1}\left\{\left[\left(n^{3}-\delta_{t-1}^{3}\right) / 3\left(n-\delta_{t-1}\right)\right]-\delta_{t-1} n\right\} \cdot(A 10)
\end{aligned}
$$


Then, use text equation (19) for $\pi_{t-1}$ in (A10) and that result in (A4) to obtain text equation (20a).

Output variance during the fixed-rate regime which may collapse but has not is

$$
E_{t-1}\left[\left(y_{t}-E_{t-1} y_{t}\right)^{2} \mid N C_{t}\right]=\beta^{2}\left[\bar{s}-E_{t-1} s_{t}\right]^{2}+\sigma_{u}^{2} \text {. }
$$

But, $\bar{s}-E_{t-1} s_{t}=\pi_{t-1}\left[\bar{s}-E_{t-1}\left(\tilde{s}_{t} \mid C_{t}\right)\right]$. Therefore,

$E_{t-1}\left[\left(y_{t}-E_{t-1} y_{t}\right)^{2} \mid N C_{t}\right]=\beta^{2} \pi_{t-1}^{2}\left[\bar{s}-E_{t-1}\left(\tilde{s}_{t} \mid C_{t}\right)\right]^{2}+\sigma_{u}^{2}$, and we may use previous results of the Appendix to obtain

$$
E_{t-1}\left[\left(y_{t}-E_{t-1} y_{t}\right)^{2} / N C_{t}\right]=\beta^{2}\left(\eta-\delta_{t-1}\right)^{4} / 16 \eta^{2}+\sigma_{u}^{2},
$$

which is equation (20c) in the text.

\section{AII. PROPERTIES OF FIGURR 1}

The curve labeled (20a) in Figure 1 plots $v_{t-1}\left(y_{t}\right) / C$. Fix as a function of $\delta_{t-1}$. It has maximum value at $\delta_{t-1}=-\eta$ of $\frac{B^{2} \eta^{2}}{3}+\sigma_{u}^{2}$ and a minimum at $\delta_{t-1}=n$ of $\sigma_{u}^{2}$. The slope of the function is

$$
\frac{\beta}{4 \eta^{2}}\left(\eta-\delta_{t-1}\right)\left(\delta_{t-1}^{2}-\eta^{2}\right)<0
$$

since $\left|\delta_{t-1}\right|<n$. The derivative of the slope is

$$
\frac{B^{2}}{4 n^{2}}\left[\left(n^{2}-\delta_{t-1}^{2}\right)+2\left(n-\delta_{t-1}\right) \delta_{t-1}\right]
$$


so the curve's inflection point lies at $\delta_{t-1}<0$ since the second derivative is positive at $\delta_{t-1}=0$.

The curve labeled (20c) in Figure 1 plots $v_{t-1}\left(y_{t}\right)$ C.Fix. 2 as a function of $\delta_{t-1}$. It has a maximum value at $\delta_{t-1}=-\eta$ of $\beta^{2} \eta^{2}+\sigma_{u}^{2}$. The derivative of this function is $-\beta^{2}\left(n-\delta_{t-1}\right)^{3} / 4 n^{2}<0$ and the second derivative is $3 \beta^{2}\left(\eta-\delta_{t-1}\right)^{2} / 4 n^{2}>0$. The two curves intersect when real solutions for $\delta_{t-1}$ obtained by setting (20a) equal to (20c) lie in the range $-\eta \leqslant \delta_{t-1} \leqslant n$.

\section{A3. RESULTS FOR SECTION 3}

In this section we derive the optimal $z$ for the collapsing fixed rate regime. The general solution of (28) is

$$
z_{t-1}=-\lambda C_{t-1}\left[p_{t} ; u_{t}\right] / v_{t-1}\left(p_{t}\right)
$$

We first work on the term in the numerator of $A(13)$. When a speculative attack is possible, the expected price level reflects the probability of the attack, $\pi_{t-1}$ :

$$
\begin{gathered}
E_{t-1}\left(p_{t}\right)=\left(1-\pi_{t-1}\right) E\left[\left(p_{t-1}^{*}+v_{t}^{*}+\bar{s}\right) \mid N C_{t}\right]+ \\
\pi_{t-1} E\left[\left(p_{t-1}^{*}+v_{t}^{*}+\tilde{s}_{t}\right) \mid C_{t}\right] \\
=p_{t-1}^{*}+\left(1-\pi_{t-1}\right) \bar{s}+\pi_{t-1} E\left(\tilde{s}_{t} \mid C_{t}\right) .
\end{gathered}
$$

The conditional covariance in ( $\mathrm{Al} 3$ ) is

$$
\begin{aligned}
E_{t-1}\left[u_{t}\left(p_{t}-E_{t-1} p_{t}\right)\right] & =\left(1-\pi_{t-1}\right) E_{t-1}\left[u_{t}\left(p_{t}-E_{t-1} p_{t}\right) \mid N C_{t}\right] \\
& +\pi_{t-1} E_{t-1}\left[u_{t}\left(p_{t}-E_{t-1} p_{t}\right) \mid C_{t}\right] .
\end{aligned}
$$


Combining (A14) and (A15) gives

$$
\begin{gathered}
E_{t-1}\left[u_{t}\left(p_{t}-E_{t-1} p_{t}\right)\right]=\left(1-\pi_{t-1}\right)\left[E_{t-1}\left(u_{t} v_{t}^{*} \mid N C_{t}\right)\right. \\
\left.+\pi_{t-1}\left[\bar{s}-E_{t-1}\left(\tilde{s}_{t} \mid C_{t}\right)\right] E_{t-1}\left(u_{t} \mid N C_{t}\right)\right\}+ \\
+\pi_{t-1}\left[E_{t-1}\left(u_{t} v_{t}^{*} \mid C_{t}\right)+E_{t-1}\left[\left(\tilde{s}_{t}-\bar{s}\right) u_{t} \mid C_{t}\right]\right. \\
\left.+\pi_{t-1}\left[\bar{s}-E_{t-1}\left(\tilde{s}_{t} \mid C_{t}\right)\right] E_{t-1}\left(u_{t} \mid C_{t}\right)\right\} .
\end{gathered}
$$

Since $E_{t-1}\left(u_{t} v_{t}^{*}\right)=\left(1-\pi_{t-1}\right) E_{t-1}\left(u_{t} v_{t}^{*} \mid N C_{t}\right)+\pi_{t-1} E_{t-1}\left(u_{t} v_{t}^{*} \mid c_{t}\right)=0$, and $E_{t-1}\left(u_{t}\right)=\left(1-\pi_{t-1}\right) E_{t-1}\left(u_{t} \mid N C_{t}\right)+\pi_{t-1} E_{t-1}\left(u_{t} \mid C_{t}\right)=0$, we may write (A16) as

$$
E_{t-1}\left[u_{t}\left(p_{t}-E_{t-1} p_{t}\right)\right]=\pi_{t-1} E_{t=1}\left[u_{t}\left(\tilde{s}_{t}-\bar{s}\right) \mid C_{t}\right]
$$

which is used in the numerator of text equation (31).

For later calculations it is useful to recall from the text that $\tilde{s}_{t}-\bar{s}=\left[\gamma_{t-1}-u_{t}-v_{t}^{*}\right]$, where $\gamma_{t-1} \equiv\left[\tilde{m}-p_{t-1}^{*}-\alpha-\bar{s}\right]$.

Hence,

$$
-\lambda C_{t-1}\left(p_{t}-E_{t-1} p_{t} ; u_{t}\right)=-\lambda \pi_{t-1}\left\{\gamma_{t-1} E_{t-1}\left(u_{t} \mid C_{t}\right)-E\left(u_{t}^{2} \mid C_{t}\right)-E\left(v_{t}^{*} u_{t} \mid C_{t}\right)\right\}
$$

We turn now to the expression in the denominator of $A(13)$. A derivation similar to that above gives 


$$
\begin{gathered}
\left.E_{t-1}\left(p_{t}-E_{t-1} p_{t}\right)^{2}\right]=\sigma_{v^{*}}^{2}+\pi_{t-1} E_{t-1}\left[\left(\tilde{s}_{t}-\vec{s}\right)^{2} \mid C_{t}\right]-\pi_{t-1}^{2}\left[\left(\vec{s}-E_{t-1}\left(\tilde{s}_{t} \mid C_{t}\right)\right]^{2}\right. \\
+2 \pi_{t-1} E_{t-1}\left[\left(\tilde{s}_{t}-\vec{s}\right) v_{t}^{*} \mid C_{t}\right] .
\end{gathered}
$$

It will prove useful to expand some of the terms on the right hand side of (A19). In particular, consider the following terms:

$$
\begin{aligned}
& E_{t-1}\left[\left(\tilde{s}_{t}-\bar{s}\right)^{2} \mid C_{t}\right]=Y_{t-1}{ }^{2}-2 \gamma_{t-1}\left[E_{t-1}\left(u_{t} \mid C_{t}\right)+E_{t-1}\left(v_{t}^{*} \mid C_{t}\right)\right] \\
& +E_{t-1}\left(u_{t}^{2} \mid C_{t}\right)+E_{t-1}\left(v_{t}^{*} \mid C_{t}\right)+2 E_{t-1}\left(u_{t} v_{t}^{*} \mid C_{t}\right), \quad(A 20 a) \\
& {\left[\bar{s}-E_{t-1}\left(\tilde{s}_{t} \mid C_{t}\right)\right]^{2}=\gamma_{t-1}^{2}-2 \gamma_{t-1}\left[E_{t-1}\left(u_{t} \mid C_{t}\right)+E_{t-1}\left(v_{t}^{*} \mid C_{t}\right)\right]} \\
& +\left[E_{t-1}\left(u_{t} \mid C_{t}\right)+E_{t-1}\left(v_{t}^{*} \mid C_{t}\right)\right], \\
& E_{t-1}^{2}\left[\left(\tilde{s}_{t}-\bar{s}\right) v_{t}^{*} \mid C_{t}\right]=\gamma_{t-1} E_{t-1}\left(v_{t}^{*} \mid C_{t}\right)-E_{t-1}\left(u_{t} v_{t}^{*} \mid C_{t}\right)-E_{t-1}\left(v_{t}^{* 2} \mid C_{t}\right) .
\end{aligned}
$$

In order to make further progress on these expressions we assumed $u_{t}$ and $v_{t}^{*}$ to be uniformly and independently distributed on the interval $[-\pi, \pi]$. In the calculations reported here, we impose the additional assumption that $-2 n<Y_{t-1}<0$. We impose this additional restriction because the joint distribution of $\left(u_{t}, v_{t}^{*}\right)$ conditional on $u_{t}+v_{t}^{*}<Y_{t-1}$ is quite complicated when $Y_{t-1}>0$, and we need only examine a few different values of $Y_{t-1}$ to establish the point that $z_{t-1}$ will be time varying. Also, when $Y_{t-1}<-2 \pi$, the probability of a collapse is zero. 
The following results are a few basic facts concerning the joint conditional distribution of $u_{t}$ and $v_{t}$ :

$$
\begin{aligned}
& E_{t-1}\left(u_{t} \mid c_{t}\right)=E_{t-1}\left(v_{t}^{*} \mid c_{t}\right)=\left(\gamma_{t-1}-n\right) / 3 \\
& E_{t-1}\left[u_{t}^{2} \mid C_{t}\right]=E_{t-1}\left[v_{t}^{* 2} \mid C_{t}\right]=\frac{\left(\psi_{t-1} / 3\right)\left(\psi_{t-1}^{3}+\eta^{3}\right)-\left(\psi_{t-1}^{4}-\eta^{4}\right) / 4}{(1 / 2)\left(2 \eta+\gamma_{t-1}\right)^{2}} \\
& E_{t-1}\left[u_{t} v_{t}^{*} \mid c_{t}\right]=\frac{\left[\left(\gamma_{t-1}^{2}-n^{2}\right) / 2\right]\left(\psi_{t-1}^{2}-\eta^{2}\right)-\left(2 \gamma_{t-1} / 3\right)\left(\psi_{t-1}^{3}+n^{3}\right)}{\left(2 n+\gamma_{t-1}\right)^{2}}+ \\
& +\frac{\left(\psi_{t-1}^{4}-n^{4}\right) / 4}{\left(2 n+\gamma_{t-1}\right)^{2}} \\
& \sigma_{v *}^{2}=E_{t-1}\left(v_{t}^{* 2}\right)=n^{2} / 3 \\
& \pi_{t-1}=\frac{\left(\gamma_{t-1}+2 n\right)^{2}}{8 n^{2}}
\end{aligned}
$$

where $\psi_{t-1} \equiv\left(\gamma_{t-1}+n\right)$

We now rewrite (Al3) using all of the above to obtain

$$
z_{t-1}=\frac{-\pi_{t-1}{ }^{\lambda} x_{1 t-1}}{\sigma_{v *}^{2}+\pi_{t-1} x_{2 t-1}-\pi_{t-1}^{2} x_{3 t-1}+2 \pi_{t-1} x_{1 t-1}}
$$

where, for $-2 n<\delta_{t-1}<0, \pi_{t-1}$ is given in (A2le), $\sigma_{v *}^{2}$ is given in (A21d), and 
$-34-$

$$
\begin{aligned}
& x_{1 t-1}=\left[\frac{\gamma_{t-1}\left(\gamma_{t-1}-n\right)}{3}-\left\{\frac{\left(\psi_{t-1} / 3\right)\left(\psi_{t-1}^{3}+n^{3}\right)-(1 / 4)\left(\psi_{t-1}^{4}-n^{4}\right)}{(1 / 2)\left(2 n+\gamma_{t-1}\right)^{2}}\right\}\right. \\
& \left.-\left[\frac{\left[\left(\gamma_{t-1}^{2}-\eta^{2}\right) / 2\right]\left(\psi_{t-1}^{2}-n^{2}\right)-\left(2 \gamma_{t-1} / 3\right)\left(\psi_{t-1}^{3}+\eta^{3}\right)+\left(\psi_{t-1}^{4}-\eta^{4}\right) / 4}{\left(2 n+\gamma_{t-1}\right)^{2}} \quad \text { (A23a) }\right\}\right] \\
& x_{2 t-1}=\gamma_{t-1}^{2}-\left[4 \gamma_{t-1}\left(\gamma_{t-1}-n\right) / 3\right]+ \\
& +\frac{\left(\gamma_{t-1}^{2}-n^{2}\right)\left(\psi_{t-1}^{2}-n^{2}\right)+(4 n / 3)\left(\psi_{t-1}^{3}+n^{3}\right)-(1 / 2)\left[\left(\psi_{t-1}^{4}-n^{4}\right]\right.}{\left(2 n+\gamma_{t-1}\right)^{2}} \quad \text { (A23b) } \\
& \left.x_{3 t-1}=\left[(1 / 3) \gamma_{t-1}+(2 / 3) \eta\right]\right]_{0}^{2}
\end{aligned}
$$

The simulations reported in the text used $n=1$ and $\gamma_{t-1}=-2,-1,0$. 
FOOTNOTES

Early contributions to the debate on fixed versus flexible exchange rates are surveyed by Ishiyama (1975) and Tower and Willett (1976). Some of the more recent analytical contributions to this area that are based on rational expectations include Flood (1979), Lapan and Enders (1980), Helpman (1981), Weber (1981), Eaton (1982), Kimbrough (1983), Turnovsky (1983), and A1zenman and Frenkel (1984).

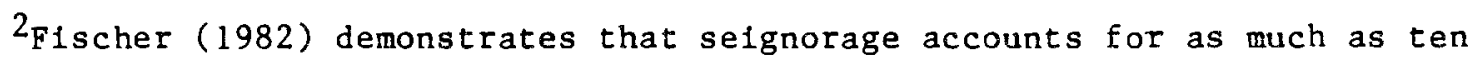
percent of total government revenue for countries such as Argentina and Braz1l. The literature on the monetary approach to the balance of payments, e.g. Frenkel and Johnson (1975), was quite clear that a policy of fixing the exchange rate made the total money supply endogenous.

${ }^{3}$ The Dorabusch model deflates nominal money balances by the domestic price of the domestic good instead of deflating them by a price index composed of the domestic price of domestic goods and the domestic price of forelgn goods. For our purposes this is a harmless simplification which we also adopt.

${ }^{4}$ Although we examine only flxed and freely floating exchange rates, our methods could easily encompass "crawling pegs" or any rule that makes the fixed exchange rate a deterministic function of the previous state. Our methods could also be extended to analyze a "dirty float" of the form $\mathrm{m}_{t}-\mathrm{m}_{t-1}=\psi \mathrm{s}_{t}+\mathrm{v}_{t}$, such as that studied by Aizenman and Frenkel (1984). In such a circumstance, while the private sector could not attack the money printing rule, the fiscal authority might require a change in the rule if it were to call for less money printing than were required for deficit finance. The inability of Southern Cone countries to stay on preannounced crawling peg schedules is perhaps an example of the type of fiscal authority attack we have in mind. In such countries an exchange rate policy seems not to be permanently viable unless it accomodates the fiscal authority's revenue requirements. 
${ }^{5}$ The conditions we use for an attack are those in Flood and Garber (1984). An alternative view, where the agents who would attack the price fixing scheme are small and disorganized is proposed by obstfeld (1984). According to the obstfeld view, $\tilde{s}_{t}>\bar{s}$ is necessary for an attack but not always sufficient. The condition is necessary and sufficient in the present model though, as Obstfeld (1984) has shown.

${ }^{6}$ Indexing wages to prices is motivated only by the large number of such contracts actually implemented. The value of the loss function can generally be made smaller if contracts include more complex indexing to the state as in Karni (1983) or Aizenman and Frenkel (1984). Our intent, however, is not to specify an ideal contract, but rather to indicate how actual contracts affect the economy in a second best environment.

${ }^{7}$ Cecchetti (1984) derives and documents changes in an implied indexing parameter for union wage changes from 1964-1978 for U. S. unionized manufacturing. The movement in the parameter may be due to movement in the conditional varlance of the exogenous monetary and real processes of the economy, but the analysis in this paper suggests that such movement might also arise from agents' perceptions of the likelihood of switches in government policies. Since the contracting paradigm also leads to the aggregate supply curve studied by Lucas (1973), the perceived impermanence of existing exchange rate regimes is an additional reason why the slope parameters would differ across countries. 


\section{REFERENCES}

Aizenman, J. and J. Frenke1, 1984, "Optimal Wage Indexation, Foreign-Exchange Intervention, and Monetary Policy," American Economic Review, Forthcoming.

Blanco, H. and P. Garber, 1984, "Recurrent Devaluation and Speculative Attacks on the Mexican Peso," University of Rochester manuscript February.

Cecchett1, S., 1984, "Indexation and Incomes Policy: A Study of Wage Adjustment in Unionized Manufacturing," Working Paper, Solomon Center, New York University.

Dornbusch, R., 1976, "Expectations and Exchange Rate Dynamics," Journal of Political Economy, 84, December, pp. 1161-76.

Eaton, J., 1982, "Optimal and Time Consistent Exchange Rate Management in an Overlapping Generations Economy," Economic Growth Center Discussion Paper 413, Yale Universtity.

Flood, R. P., 1979, "Capital Mobility and Choice of Exchange Rate System," International Economic Review 20, June, pp. 405-16.

Flood, R. and P. Garber, 1983, "A Model of Stochastic Process Switching Econometrica, May, pp. 537-52.

, 1984, "Collapsing Exchange Rate Regimes: Some Linear Examples," Journal of International Economics, August, pp. 1-14.

Flood, R. and N. Marion, 1982, "The Transwission of Disturbances Under Alternative Exchange-Rate Regimes with Optimal Indexing," Quarterly Journal of Economics, February, pp. 43-66.

, 1983, "Exchange Rate Regimes in Transition: Italy 1974," Journal of International Money and Finance, December, pp. 279-97.

Fischer, S., 1982, "Seignorage and the Case for a National Money," Journal of Political Economy, August, pp. 295-313.

Frenkel, J. and H. Johnson, 1975, The Monetary Approach to the Balance of Payments, George, Allen and Unwin.

Helpman, E., 1981, "An Exploration in the Theory of Exchange-Rate Regimes," Journal of Political Economy 89, October, pp. 865-90.

Ishiyama, Y., 1975, "The Theory of Optimum Currency Areas: A Survey," International Monetary Fund Staff Papers, July, pp. 344-83.

Karni, E., 1983, "On Optimal Wage Indexation," Journal of Political Economy Apri1, pp. 282-92. 
Kimbrough, K., 1983, "The Information Content of the Exchange Rate and the Stability of Real Output under Alternative Exchange-Rate Regimes," Journal of International Money and Finance 2, April, pp. 27-38.

Krugman, P., 1979, "A Model of Balance of Payments Crises," Journal of Money Credit and Banking, 11 , August, pp. 311-25.

Lapan, H. E. and W. Enders, 1980, "Random Disturbances and the Chotce of Exchange Regimes in an Intergenerational Model," Journal of International Economics 10, May, pp. 263-83.

Lucas, R. E. Jr., 1973, "Some Internatonal Evidence on Output-Inflation Tradeoffs," American Economic Review, 63, June, pp. 326-34.

Obstfeld, M., 1984, "Rational and Self-Fulfilling Balance-of-Payments Crises" National Bureau of Economic Research Working paper, No. 1486.

Salant, S. and D. Henderson, 1978, "Market Anticlpations of Government Gold Policies and the Price of Gold," Journal of Political Economy, 86, August, pp. $627-48$.

Tower, E. and T. D. W1llett, 1976, "The Theory of Optimum Currency Areas and Exchange-Rate Flexibility", Special Paper in International Economics No. 11, May, International Finance Section, Princeton University.

Turnovsky, S. 1983 "Wage Indexation and Exchange Market Intervention In a Smal1 Open Economy." Canadian Journal of Economics 16, November, pp. 574-92.

Weber, W., 1981, "Output Variability under Monetary Pollcy and Exchange-Rate Rules," Journal of Political Economy 89, August, pp. 733-51. 


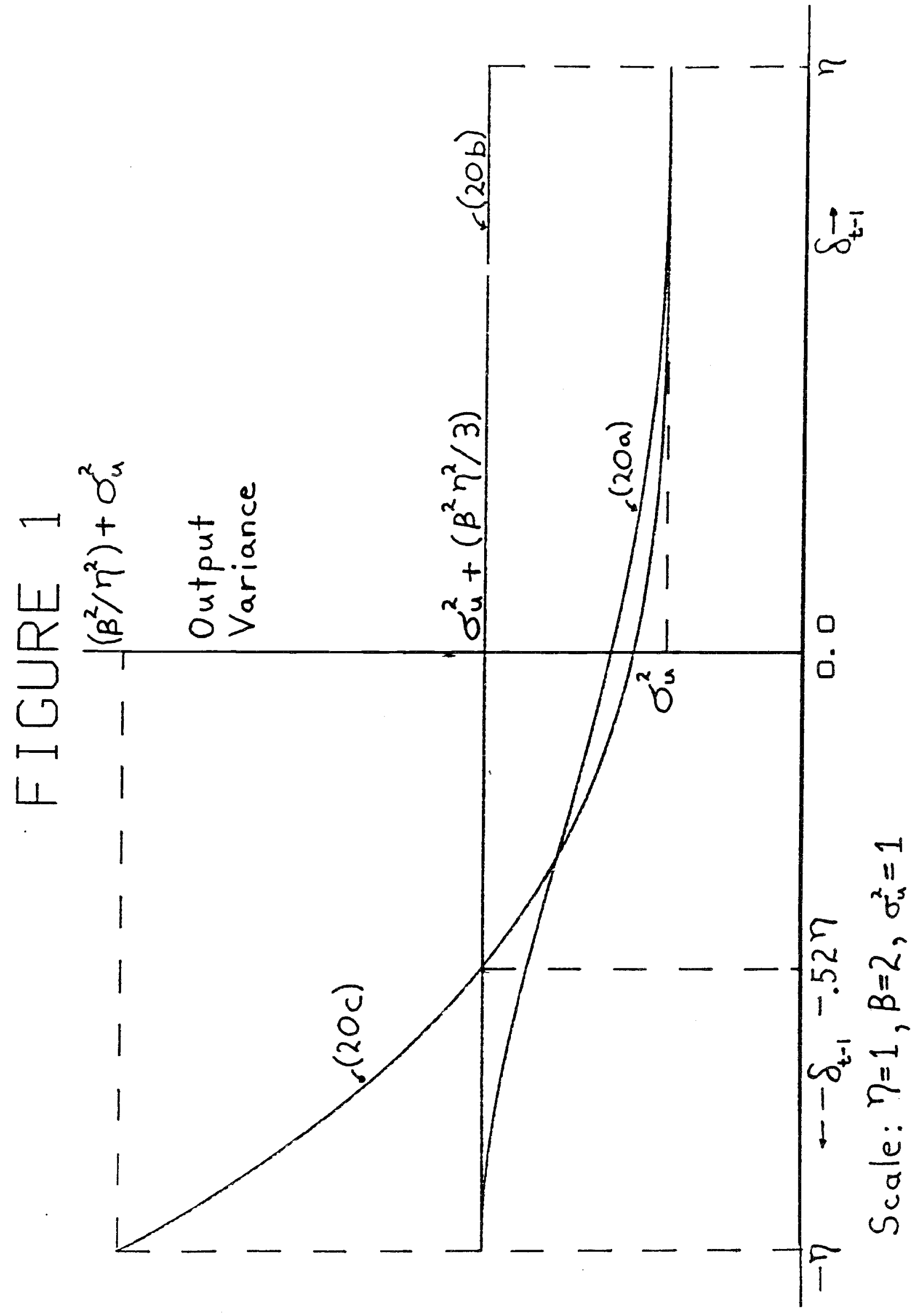

